\title{
Femtosecond lasers for laser in situ keratomileusis: a systematic review and meta-analysis
}

\author{
This article was published in the following Dove Press journal: \\ Clinical Ophthalmology \\ 7 March 2016 \\ Number of times this article has been viewed
}

\author{
Anne Huhtala' \\ Juhani Pietilä',2 \\ Petri Mäkinen ${ }^{1,2}$ \\ Hannu Uusitalo ${ }^{1-3}$ \\ 'Silmäasema Eye Hospital, ${ }^{2}$ SILK, \\ Department of Ophthalmology, \\ School of Medicine, University of \\ Tampere, ${ }^{3}$ TAUH Eye Center, Tampere \\ University Hospital, Tampere, Finland
}

Correspondence: Anne Huhtala Silmäasema Eye Hospital Tampere, Hämeenkatu 6, FIN-33I00 Tampere, Finland

Tel +358503040458

Email annemhuhtala@gmail.com
Purpose: The aim of this study was to review and meta-analyze whether there are differences between reported femtosecond (FS) lasers for laser-assisted in situ keratomileusis (LASIK) in terms of efficacy, predictability, and safety as primary outcomes and corneal flap thickness measurements and pre- and postoperative complications as secondary outcomes.

Methods: A comprehensive literature search of PubMed, Science Direct, Scopus, and Cochrane CENTRAL Trials Library databases was conducted to identify the relevant prospective randomized controlled trials of FS lasers for LASIK. Thirty-one articles describing a total of 5,404 eyes were included.

Results: Based on efficacy, IntraLase FS 10 and $30 \mathrm{kHz}$ gave the best results. Based on predictability and safety, there were no differences between various FS lasers. FEMTO LDV and IntraLase FS $60 \mathrm{kHz}$ produced the most accurate flap thicknesses. IntraLase and Wavelight SF200 had the fewest intraoperative complications. IntraLase, Visumax, and Wavelight FS200 had the most seldom postoperative complications.

Conclusion: There were dissimilarities between different FS lasers based on efficacy and intraoperative and postoperative complications. All FS lasers were predictable and safe for making corneal flaps in LASIK.

Keywords: femtosecond laser, laser in situ keratomileusis, LASIK, meta-analysis

\section{Introduction}

Laser-assisted in situ keratomileusis (LASIK) is the most commonly used refractive surgery technique for the correction of myopia, hyperopia, and astigmatism. ${ }^{1,2}$ The first phase of LASIK, the creation of a corneal flap, is the most critical step of LASIK, and it affects the visual outcome of the whole procedure. The flap creation is followed by excimer laser ablation of the exposed stroma after which the flap is repositioned. The technological evolution of flap creation has emerged from mechanical manually guided microkeratomes to automated microkeratomes and single-use microkeratomes, and most recently to femtosecond (FS) laser technology. ${ }^{3,4}$ In the FS laser technology, FS laser photodisrupts tissue at a preset depth and produces microcavitation bubbles consisting of water and carbon dioxide..$^{5}$ The expansion of these bubbles separates the corneal lamellae and forms a resection plane. ${ }^{5}$

There are several FS lasers on the market. IntraLase, now produced by Abbott Medical Optics Inc. (Santa Ana, CA, USA), was the first FS laser keratome introduced in the USA in $2001 .^{6}$ Technolas Femtosecond Workstation, formerly known as Femtec, by Technolas Perfect Vision (Munich, Germany), was introduced immediately after the market launch of IntraLase. ${ }^{7}$ FEMTO LDV by Ziemer Ophthalmic Systems (Port, Switzerland) was introduced in the late 2005, and Visumax by Carl Zeiss Meditec AG (Jena, Germany) in the fall 2006. ${ }^{7}$ Wavelight FS200 by Alcon Laboratories, Inc. (Fort Worth, TX, USA) 
received the US Food and Drug Administration clearance for marketing in the USA in the late $2010 .^{8}$

FS laser technology has been increasingly used in LASIK. According to a poll conducted in $2006,>30 \%$ of the LASIK flaps were created by FS laser, ${ }^{9}$ while according to a MarketScope's second-quarter survey for the year 2010, 70\% of the LASIK flaps were created using an FS laser. ${ }^{10}$ As the published meta-analysis studies for FS lasers for LASIK have been concentrated only on IntraLase, ${ }^{10,11}$ the current study was undertaken to review and meta-analyze whether there are differences between reported FS lasers for LASIK in terms of efficacy, predictability, and safety as primary outcomes and corneal flap thickness measurements (difference from the target flap thickness and combined standard deviation [SD]) and complications as secondary outcomes.

\section{Materials and methods}

\section{Literature search strategy}

Comprehensive literature searches of PubMed and Science Direct databases were first conducted on December 2, 2013. The literature search of Scopus database was conducted on March 10, 2014, and another literature search of the Cochrane CENTRAL Trials database on October 4, 2014. After the review process, all the databases were rechecked on December 28, 2015, for newer publications. The literature searches were conducted by using the following terms: "femtosecond laser lasik clinical controlled randomized" and "femtosecond laser lasik flap thickness controlled randomized" without date limitations. Language was restricted to English. Citations initially selected were first retrieved as titles by one reviewer (AH). After the initial screening, potentially relevant articles were retrieved as abstracts and screened by all authors. After this step, relevant articles were retrieved as complete papers and assessed for compliance.

\section{Quality scoring}

The quality of each study was assessed using the Jadad et $\mathrm{al}^{12}$ score with a scale of $0-5$. Each study was assessed by three main aspects of study design: randomizing, masking, and participant withdrawals/dropouts. One point was given for the presence of randomizing, masking, and participant withdrawals/dropouts. If randomizing and blinding were appropriate, one additional point was added to each. Studies scoring $<3$ points were considered to be of low quality.

\section{Outcome measures}

The primary outcome measures were efficacy, predictability, and safety. The efficacy measure was the proportion of eyes achieving an uncorrected distance visual acuity (UDVA), an UDVA of 20/20 or better. The predictability measure was refraction within \pm 0.5 diopters (D) of mean target spherical equivalent refraction. The safety measure was a loss of $\geq 2$ Snellen lines of CDVA, a corrected distance visual acuity. Secondary outcome measures were flap thickness measurements (mean flap thickness and flap predictability as SD), and intraoperative and postoperative complication rates. For primary outcome measures, hyperopic eyes were excluded from the analysis.

\section{Statistical methods}

The data were pooled together for different FS lasers. Percentage values were calculated back to basic count values in order to make nonparametric analysis possible. Statistical significance for efficacy, predictability, safety, and intra- and postoperative complications was evaluated with the chi-square test. Corneal flap thickness measurements were also pooled together and analyzed with the one-way analysis of variance (ANOVA) (SigmaPlot; Systat Software Inc., San Jose, CA, USA). In this meta-analysis, which included several previously published studies, $P$-value $<0.001$ was considered significant.

\section{Results}

\section{Results of the literature search}

Figure 1 shows the flowchart of the studies from the initial literature search to the final inclusion. Based on the full paper review, 21 controlled randomized trials and ten prospective or retrospective nonrandomized studies were included in the meta-analysis.

\section{Primary outcome measures}

Table 1 shows the main preoperative characteristics of the 31 studies describing a total of 5,404 eyes included in the meta-analysis. Studies written in bold (nine studies) have been included in the previously published meta-analysis studies $^{10,11}$ concerning FS laser for LASIK. Postoperative characteristics for primary and secondary outcomes are presented in Table 2.

\section{Efficacy}

Among the different IntraLase types, the efficacy ranged from $85.1 \%$ (IntraLase FS $60 \mathrm{kHz}$, seven studies included $^{13-19}$ ) to $100 \%$ (IntraLase FS $10^{20}$ and $30 \mathrm{kHz},{ }^{21}$ Figure 2). For the most commonly reported IntraLase FS $60 \mathrm{kHz}$, the average efficacy was $85.1 \%$. In one study, IntraLase FS 60 or $150 \mathrm{kHz}^{22}$ was used and its efficacy was $98.3 \%$. For IntraLase $150 \mathrm{kHz},{ }^{19,23-25}$ the average 


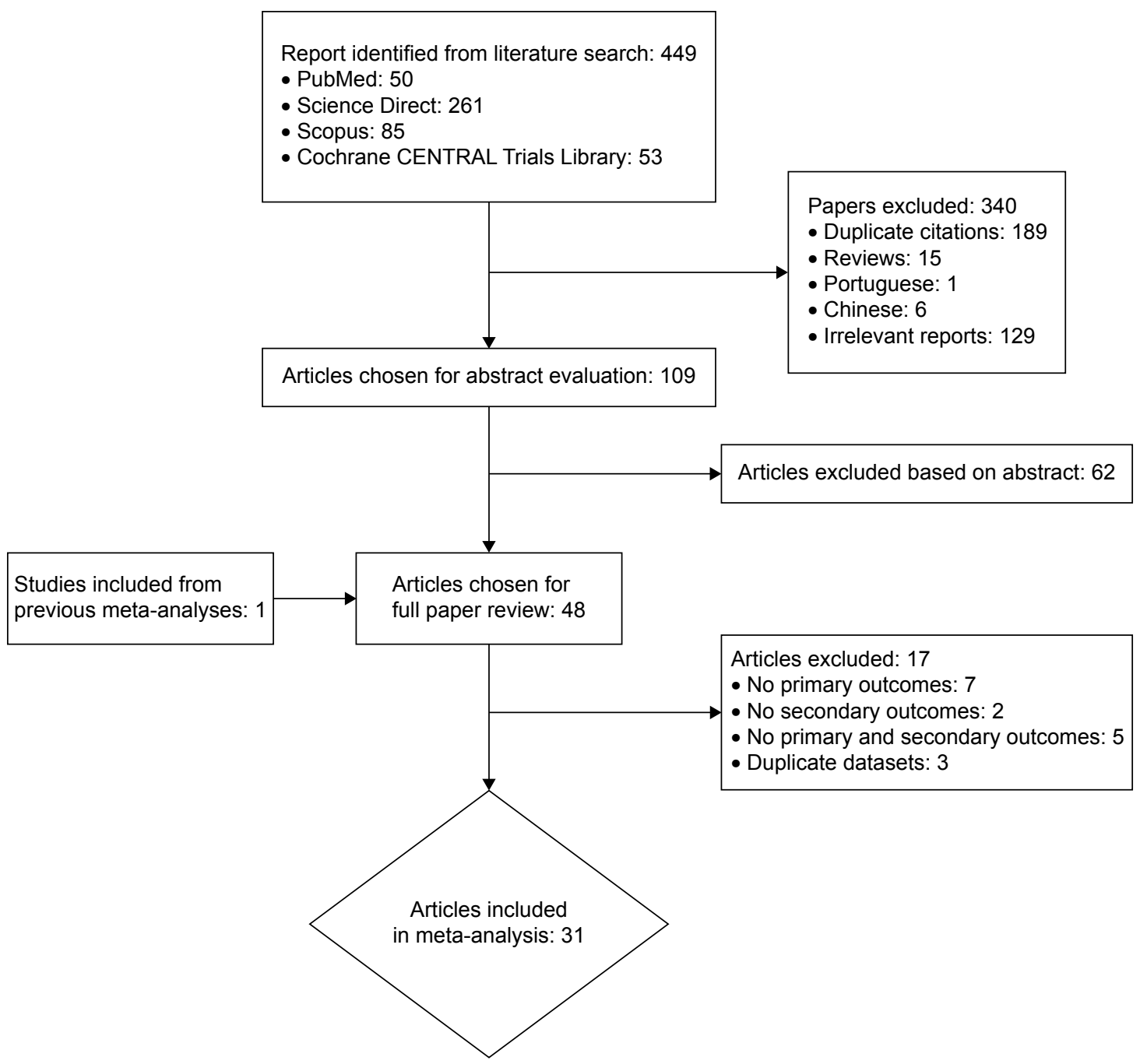

Figure I Flowchart of study selection.

efficacy was $93.7 \%$. For FEMTO LDV,${ }^{26,27}$ the average efficacy was $91.3 \%$. For Visumax ${ }^{18,24,28}$ and Wavelight FS200, ${ }^{29,30}$ the average efficacy rates were $79.1 \%$ and $83.6 \%$, respectively.

\section{Predictability}

The average predictability for the different IntraLase types ranged from $91.0 \%$ (IntraLase FS $60 \mathrm{kHz}^{14-19}$ ) to $95.9 \%$ (IntraLase FS 30 kHz; ${ }^{21,31}$ Figure 3). FEMTO LDV ${ }^{26,27}$ had the average predictability of $89.4 \%$. For Visumax ${ }^{18,24}$ and Wavelight FS200, ${ }^{29,30}$ the average predictabilities were $87.1 \%$ and $90.5 \%$, respectively.

\section{Safety}

The average safety percentage was zero or very close to zero for all the studied FS laser types (Figure 4). For IntraLase FS $15^{32-36}$ and $30 \mathrm{kHz},{ }^{21,31,37}$ the average safety was
$0.4 \%$ and $0.7 \%$, respectively. For IntraLase FS $60 \mathrm{kHz},{ }^{13-18}$ it was $0.2 \%$. For Wavelight FS $200,,^{29,30}$ it was $0.5 \%$.

\section{Secondary outcome measures}

\section{Flap thickness measurements}

The average difference from the target flap thickness for IntraLase FS $30^{31,37}$ and $60 \mathrm{kHz}^{13,14,16,38-40}$ was +0.8 and $+0.6 \mu \mathrm{m}$, respectively (Figure 5). For IntraLase FS $15 \mathrm{kHz},{ }^{33,34,41}$ the average difference from the target flap thickness was much bigger, $+6.7 \mu \mathrm{m}$. For FEMTO LDV, ${ }^{26,40,42}$ the average difference from the target flap thickness was $5.3 \mu \mathrm{m}$ less than intended. For Visumax, ${ }^{28,40}$ the difference from the target was $10.6 \mu \mathrm{m}$ more than intended. Wavelight FS20029,30 produced corneal flaps that were close to the intended value (difference from the target flap thickness was $+0.03 \mu \mathrm{m})$. The average SD for IntraLase FS 15 and $30 \mathrm{kHz}$ was 15.5 and $13.8 \mu \mathrm{m}$, respectively. For the most 


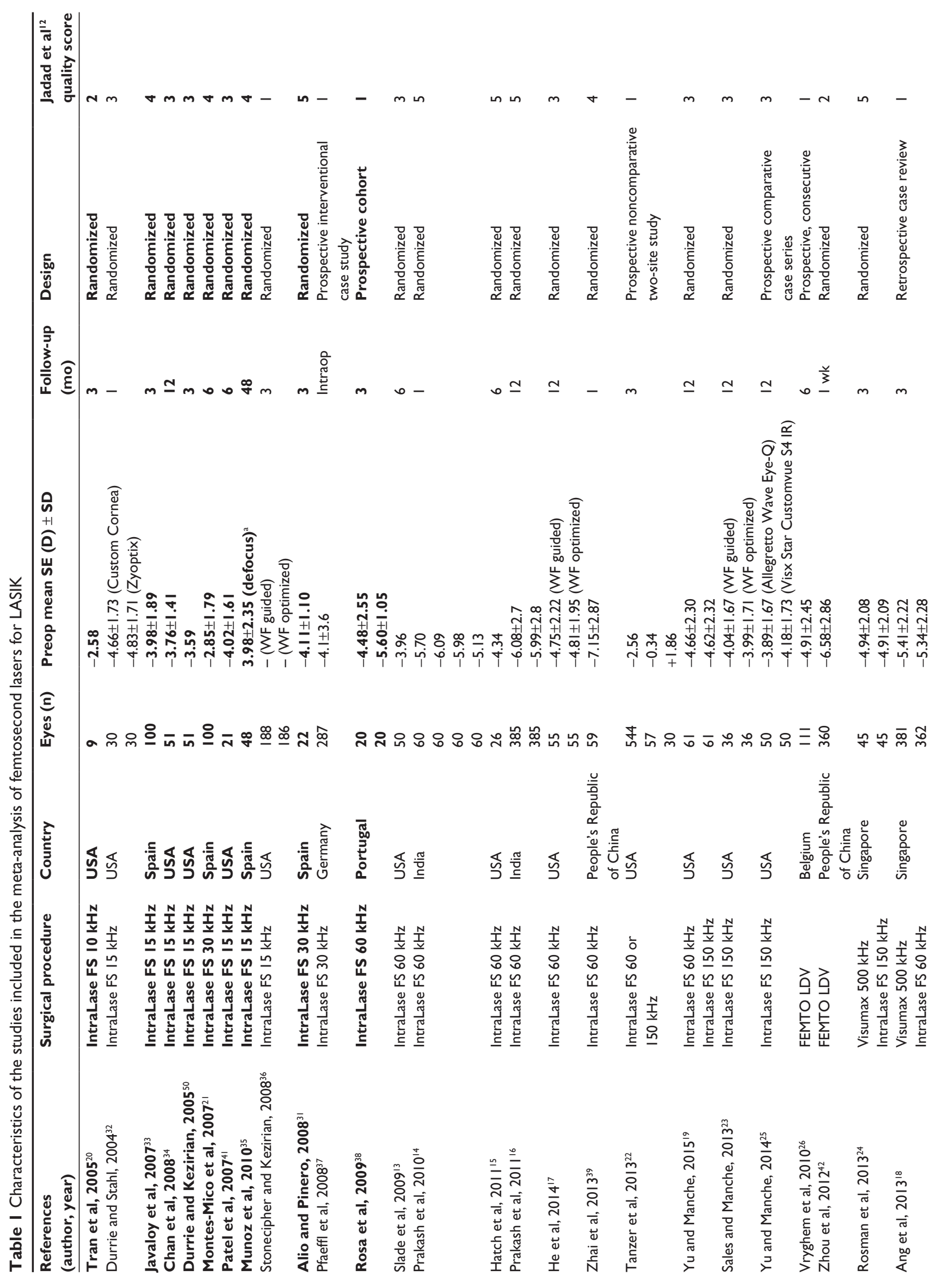




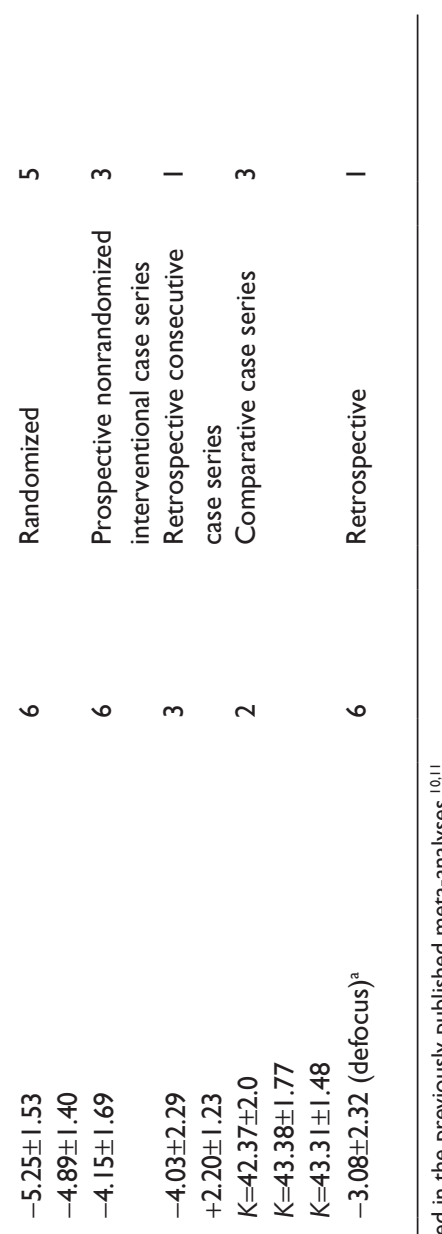

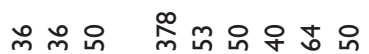

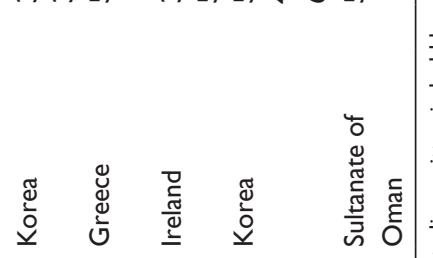

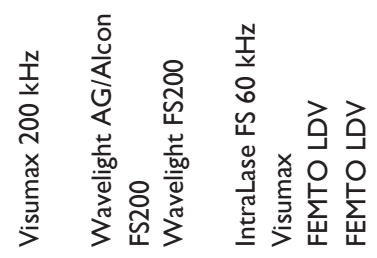

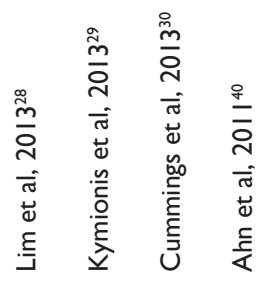

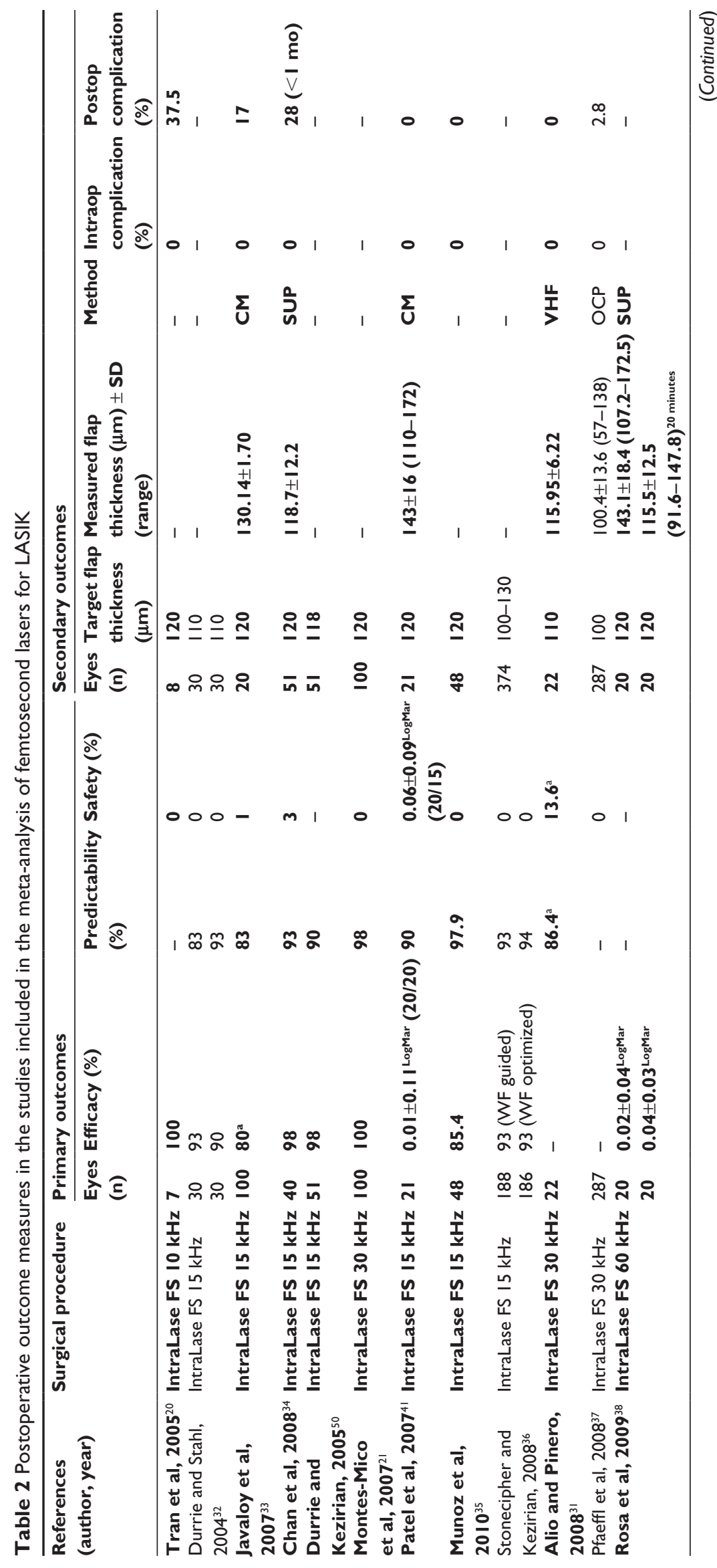




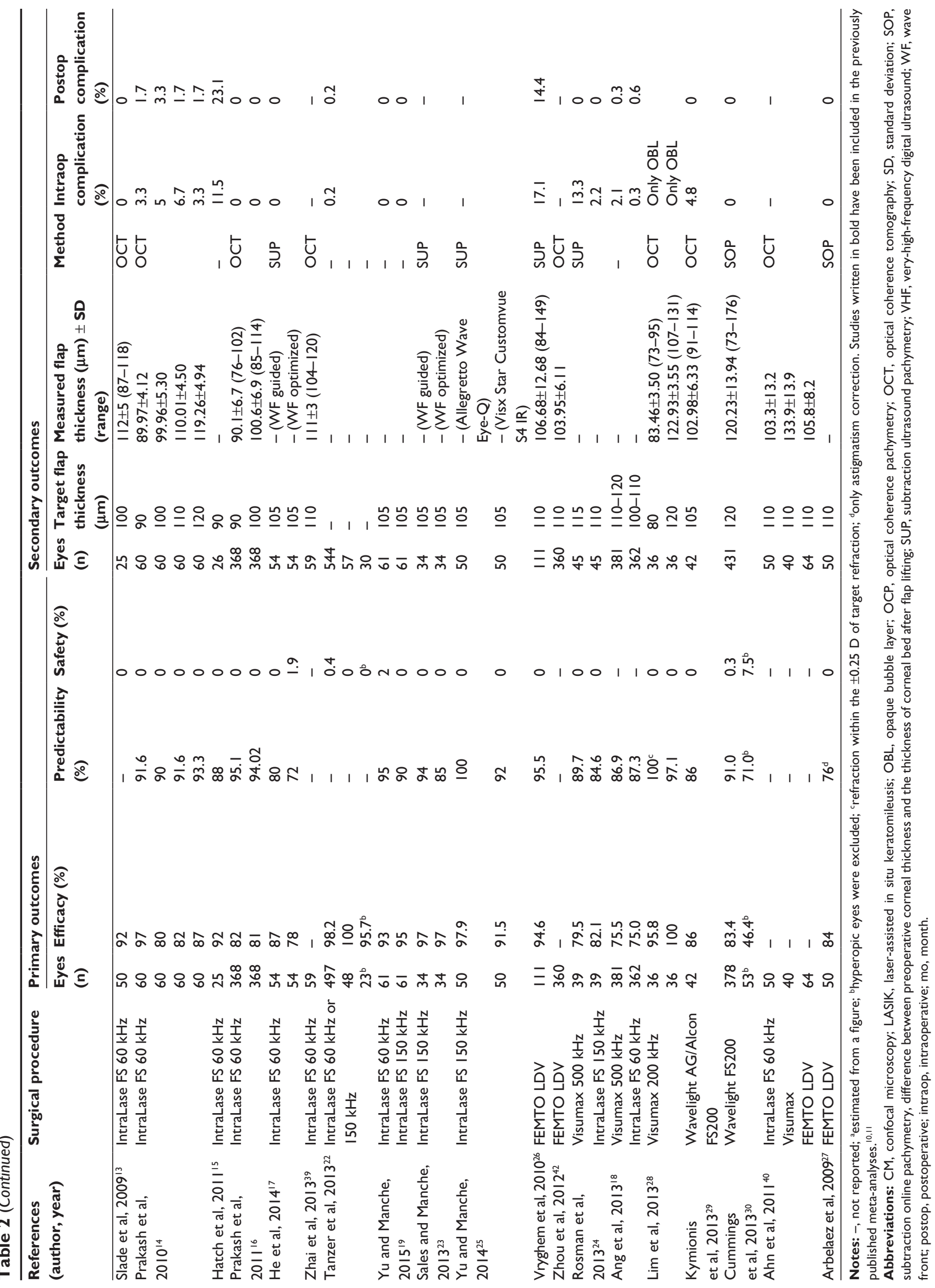




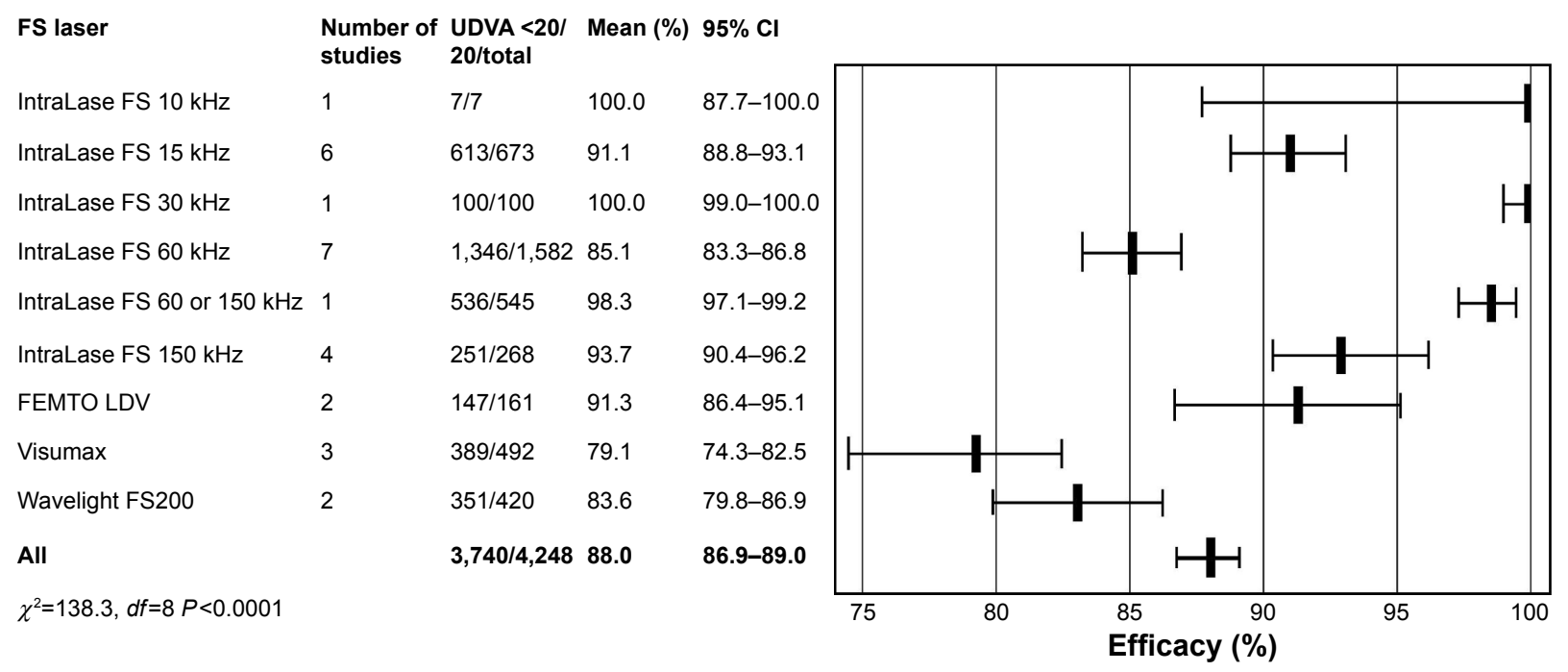

Figure 2 Efficacy, the proportion of eyes within UDVA $\geq 20 / 20$ after FS laser for LASIK.

Abbreviations: $\chi^{2}$, chi-square statistic; $\mathrm{Cl}$, confidence interval; $d f$, degrees of freedom; FS, femtosecond; LASIK, laser-assisted in situ keratomileusis; UDVA, uncorrected distance visual acuity.

studied IntraLase FS $60 \mathrm{kHz}$, the average SD was $12.4 \mu \mathrm{m}$. For FEMTO LDV, the reproducibility, the average SD was $8.2 \mu \mathrm{m}$. For Visumax, the average SD was $23.3 \mu \mathrm{m}$ and for Wavelight FS200 $14.3 \mu \mathrm{m}$.

\section{Complication rates}

Among the different IntraLase types, IntraLase FS $10 \mathrm{kHz}^{20}$ had no intraoperative complications, but postoperative complication rate was $37.5 \%$ (one study was included; Figures 6 and 7). IntraLase FS $15 \mathrm{kHz}^{33-35,41}$ had no intraoperative complications, but the average postoperative complication rate was $18.0 \%$.
IntraLase FS $30 \mathrm{kHz}^{31,37}$ had no intraoperative complications, while the percentage for postoperative complication was $2.6 \%$. IntraLase FS $60 \mathrm{kHz}^{13-19}$ had the average intraoperative and postoperative complication rates of $1.4 \%$ and $3.2 \%$, respectively. IntraLase $150 \mathrm{kHz}^{19,24}$ had the average intraoperative complication rate of $0.9 \%$ and postoperative complication rate of $0 \%$. FEMTO $\mathrm{LDV}^{26,27}$ had the average intraoperative complication rate of $11.8 \%$. The postoperative complication rate for FEMTO LDV averaged 9.9\%. For Visumax, ${ }^{24,28}$ intraoperative and postoperative complication rates averaged $3.3 \%$ and $0.2 \%$, respectively. Wavelight FS200 29,30 had the lowest

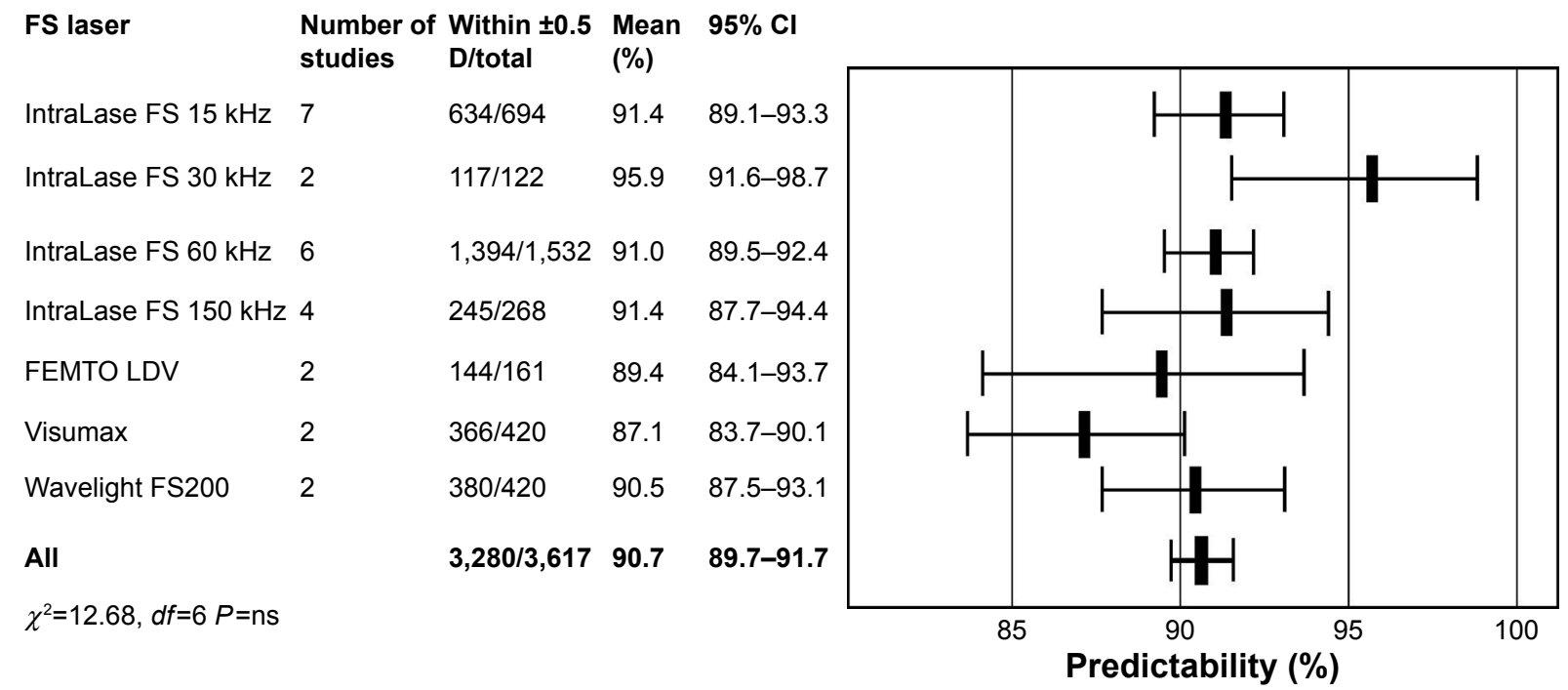

Figure 3 Predictability, the proportion of eyes within $\pm 0.5 \mathrm{D}$ of target refraction after FS laser for LASIK.

Abbreviations: $\chi^{2}$, chi-square statistic; Cl, confidence interval; D, diopters; $d f$, degrees of freedom; FS, femtosecond; LASIK, laser-assisted in situ keratomileusis; ns, nonsignificant. 


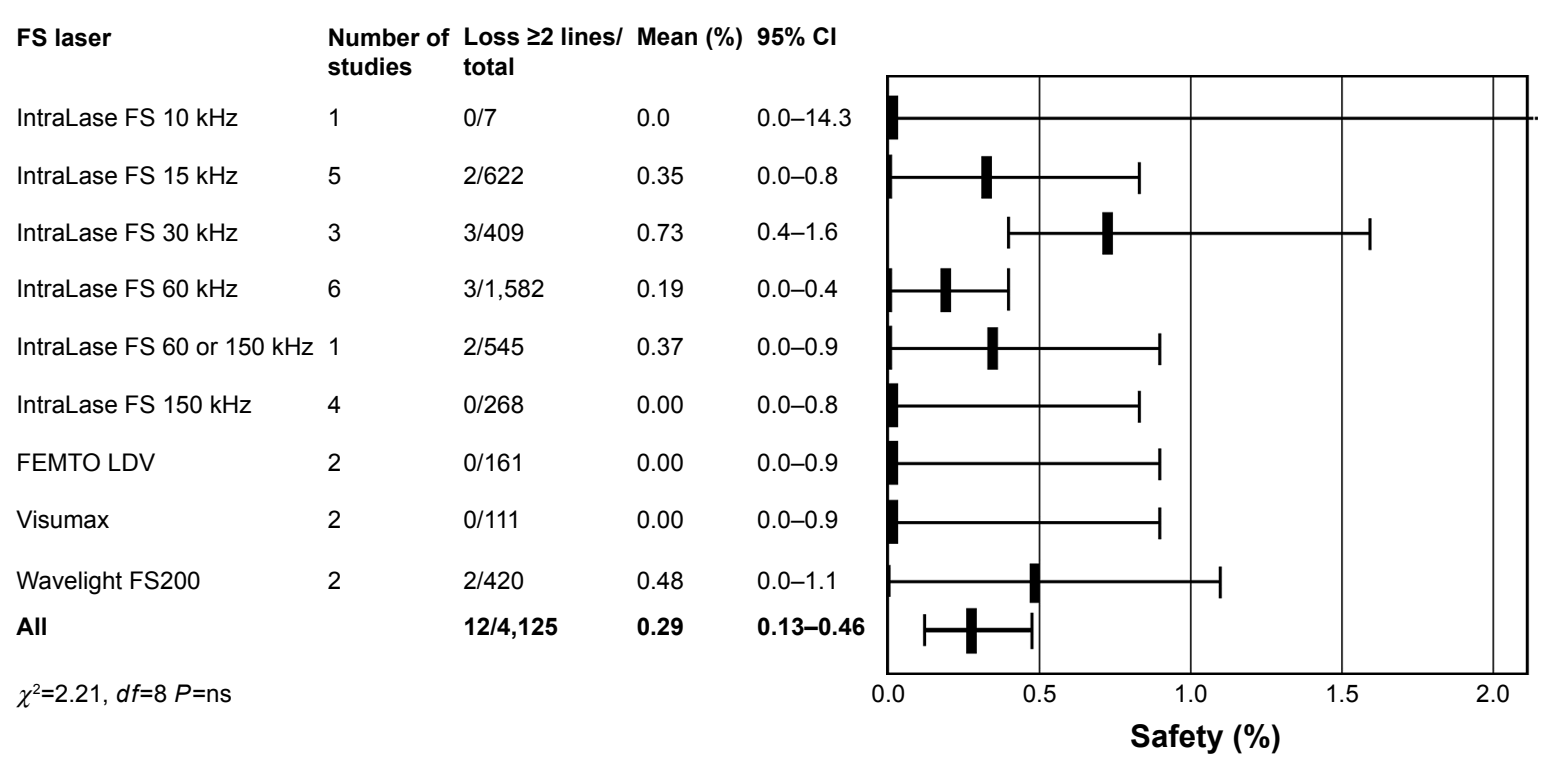

Figure 4 Safety, the proportion of eyes losing two or more Snellen lines of CDVA after FS laser for LASIK.

Abbreviations: CDVA, corrected distance visual acuity; $\chi^{2}$, chi-square statistic; $\mathrm{Cl}$, confidence interval; $d f$, degrees of freedom; FS, femtosecond; LASIK, laser-assisted in situ keratomileusis; ns, nonsignificant.

intraoperative and postoperative complication rates of $0.4 \%$ and $0 \%$, respectively.

\section{Discussion}

This meta-analysis compared different types of FS lasers for LASIK. In the literature search, we found 109 potentially relevant abstracts for review, but only 47 were suitable for a full paper review. Additionally, we included one study ${ }^{33}$ from the previously published meta-analyses. ${ }^{10,11}$ From these 48 articles, we excluded 17 papers based on lacking or duplicate data, and the final analysis included 31 articles. For primary outcome measures, hyperopic eyes were excluded. No studies were excluded from the analysis due to the lowquality scoring by Jadad et al system. ${ }^{12}$
The different FS laser systems can be classified into two groups: one group is characterized with high pulse energy-low pulse frequency (such as IntraLase and Femtec) and the other with low pulse energy-high pulse frequency (such as FEMTO LDV and Wavelight FS200). ${ }^{7}$ In the FS laser technology in the high pulse energy-low pulse frequency group, pulse energies are in the range of $1 \mu \mathrm{J}$ and repetition rates on the order of kilohertz. ${ }^{7}$ The low pulse energy-high pulse frequency system delivers only pulse energy on the order of nano-joule and uses megahertz repetition rates. ${ }^{7}$ From all FS lasers on the market, IntraLase was the first introduced and different IntraLase FS types $(10,15,30,60$, and $150 \mathrm{kHz})$ are the most commonly reported.

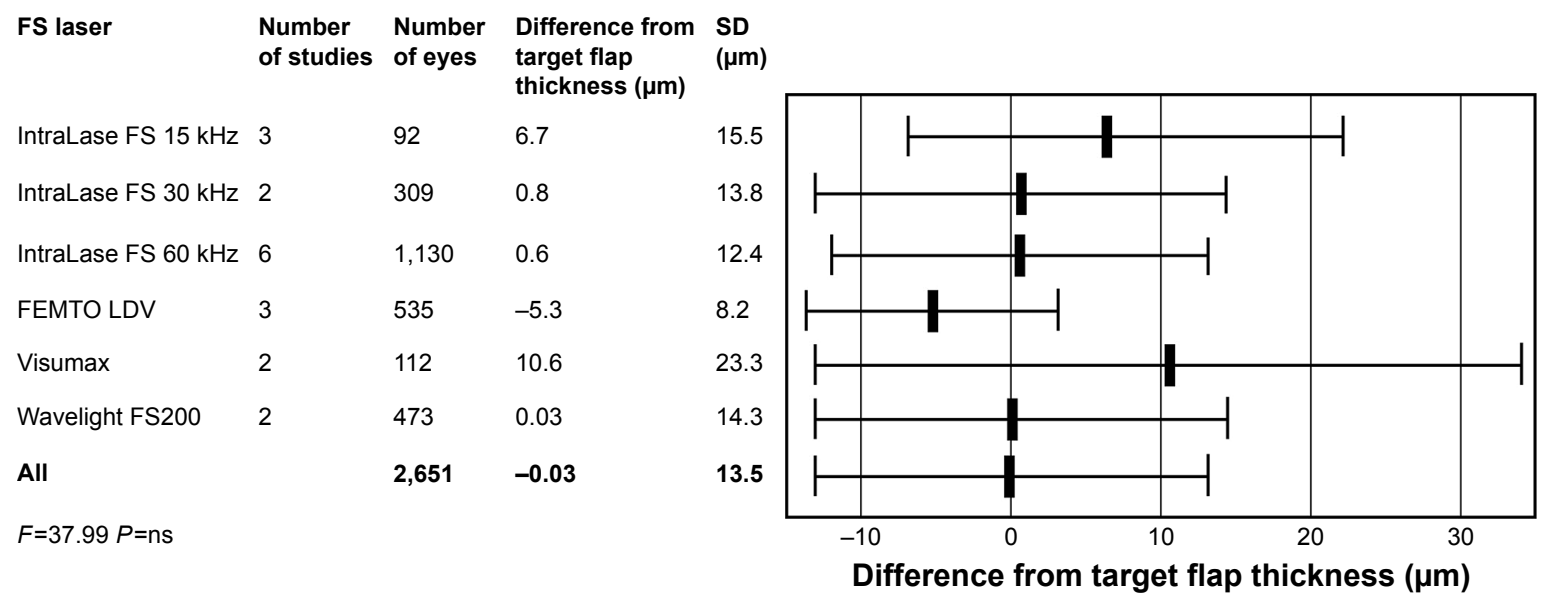

Figure $\mathbf{5}$ Corneal flap measurements after FS laser for LASIK.

Abbreviations: F, F factor; FS, femtosecond; LASIK, laser-assisted in situ keratomileusis; ns, nonsignificant; SD, standard deviation. 


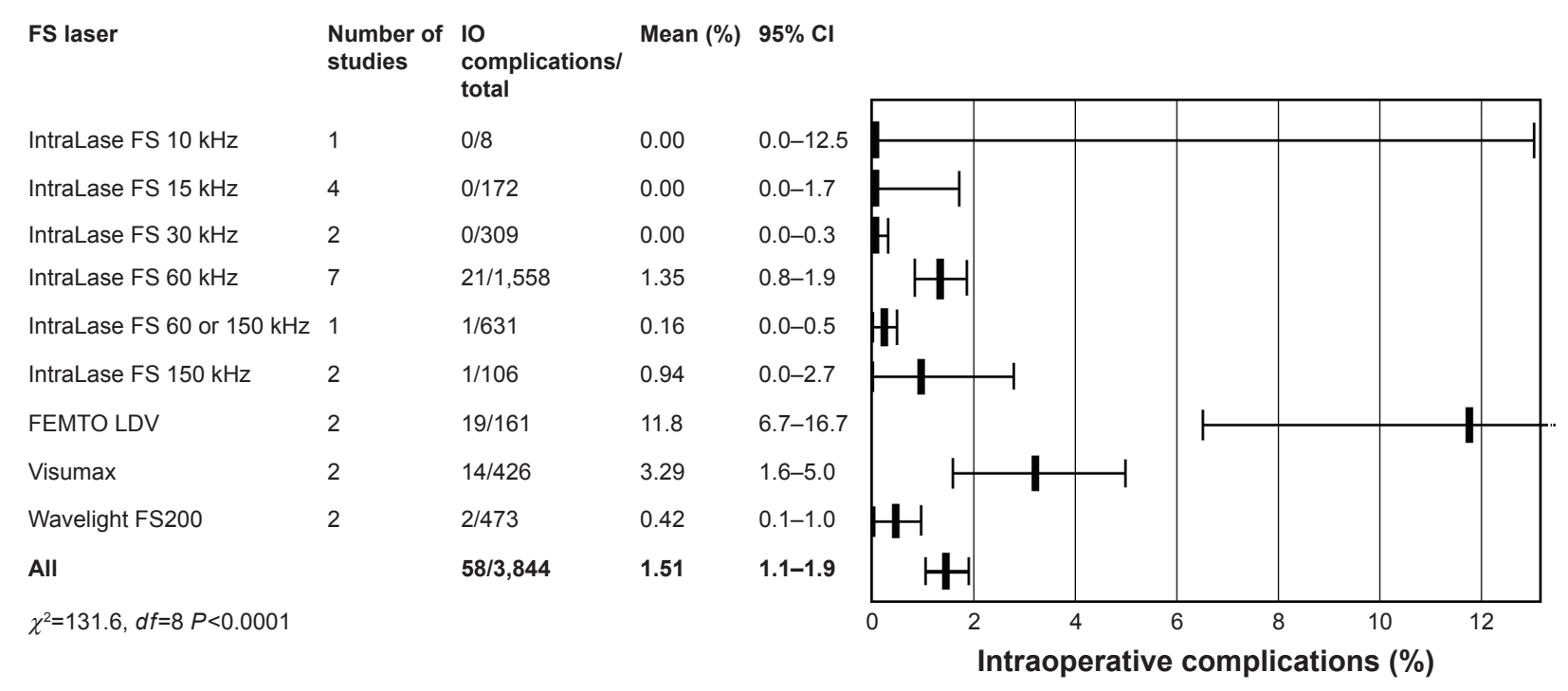

Figure 6 Intraoperative complications after FS laser for LASIK.

Abbreviations: $\chi^{2}$, chi-square statistic; $\mathrm{Cl}$, confidence interval; $d f$, degrees of freedom; FS, femtosecond; IO, intraoperative; LASIK, laser-assisted in situ keratomileusis.

The pooled primary outcome results showed that there was a statistically significant difference in the proportion of eyes within a UDVA of 20/20 or better (efficacy). Based on efficacy, IntraLase and FEMTO LDV gave the best results. There were also statistically significant differences in the mean spherical equivalent refraction within $\pm 0.5 \mathrm{D}$ of target refraction (predictability). Based on predictability, IntraLase types FS 15, FS 30, and FS $60 \mathrm{kHz}$ were the best. There was no statistically significant difference in the loss of $\geq 2$ Snellen lines of CDVA (safety) between different FS lasers.

It was difficult to combine the results of randomized controlled trials because of different follow-up times. In the 31 studies chosen for this meta-analysis, the follow-up time was $\leq 1$ month in five studies..$^{14,32,37,39,42}$ The most commonly reported follow-up times were 3 months (ten studies) ${ }^{18,20,22,24,30,31,33,36,38,50}$ and 6 months (eight studies). . $^{13,15,21,26-29,41}$ The follow-up time was $\geq 1$ year only in seven cases. ${ }^{16,17,19,23,25,34,35}$ Long follow-up times should be recommended for reporting refractive results, especially in controlled randomized studies. In the metaanalysis, different excimer laser choices used in LASIK made it also more difficult to compare refractive results. Another drawback of this meta-analysis is that due to limited reporting, the results were pooled together from standard, wavefrontguided, and wavefront-optimized treatments, and there was no compensation for this.

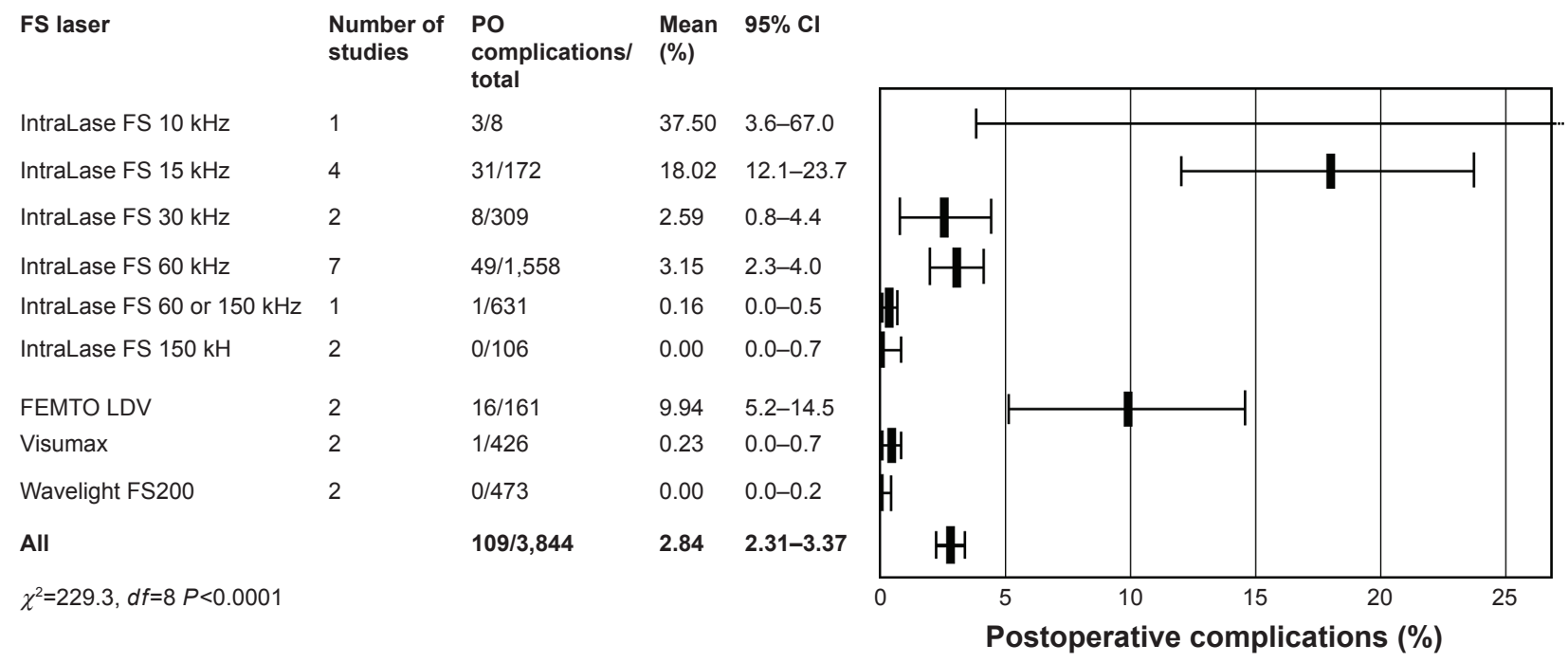

Figure 7 Postoperative complications after FS laser for LASIK.

Abbreviations: $\chi^{2}$, chi-square statistic; $\mathrm{Cl}$, confidence interval; df, degrees of freedom; FS, femtosecond; LASIK, laser-assisted in situ keratomileusis; PO, postoperative. 
Mechanical microkeratomes typically create meniscusshaped flaps that are thinner in the center and thicker in the periphery, whereas FS laser flaps have been found to be typically more uniformly planar. ${ }^{43-47}$ Preliminary studies with the IntraLase FS laser have demonstrated that free flaps, irregular flaps, microperforations, decentered flaps, epithelial defects, and abrasions were significantly reduced or eliminated. ${ }^{48-50}$ The SD of achieved flap thickness with FS lasers has also been found to be narrower than with mechanical systems. ${ }^{4,46}$

Although in this meta-analysis flap thickness measurements and complication rates were classified as secondary outcomes from the surgeons' point of view, they are in fact the areas of major concern in LASIK. In the meta-analysis, the pooled secondary outcome results showed some variations between different FS lasers. Based on the SD of the measured flap thicknesses, FEMTO LDV reproduced the most accurate flap thicknesses.

Certain complications have been shown to be unique to the FS laser, such as transient opaque bubble layer (OBL), ${ }^{51-55}$ especially with the IntraLase, transient light sensitivity syndrome, ${ }^{56,57}$ increased corneal backscatter, ${ }^{41}$ and rainbow glare. ${ }^{58-60}$ The incidence of transient OBL, transient light sensitivity syndrome, and rainbow glare has reduced with lower energies used. In this meta-analysis, IntraLase and Wavelight SF200 had the fewest intraoperative complications. IntraLase FS $60 \mathrm{kHz}$, Visumax, and Wavelight FS200 had the most seldom postoperative complications. In the meta-analysis, it was difficult to compare the complications based on the percentage of complications reported in the studies. In general, there were very few intraoperative complications reported. The most common intraoperative complications were a loss of suction, OBL, and adhesions. The most frequently reported postoperative complications were diffuse lamellar keratitis and microstriae. No ectasia was found in these studies. However, there seemed to be big differences between authors in reporting complications in LASIK. For instance, in the first FEMTO LDV study that reported the results of a preproduction FS laser system, its intraoperative complication rate was $17.1 \%$ and postoperative complication rate was $14.4 \%{ }^{26}$ Furthermore, there was a mild epithelial sloughing in $11.8 \%$ of the eyes. Yet, in another FEMTO LDV study, there were no complications. ${ }^{27}$ Therefore, we suggest a standardized system for reporting complications in refractive surgery. Intraoperative side effects that do not have any effects on the refractive outcome should also be reported, such as OBL, decentered, incomplete or free flaps, and flap adhesion. Bleeding from the limbal vessels should also be reported.

\section{Conclusion}

In conclusion, there were dissimilarities between different FS lasers based on efficacy and intraoperative and postoperative complications. All FS lasers were predictable and safe for making corneal flaps in LASIK.

\section{Acknowledgment}

Dr Matti Kataja is acknowledged for his statistical and graphical expertise.

\section{Disclosure}

Dr Pietilä has financial interest in the Ziemer Ophthalmic Systems. The other authors report no conflicts of interest in this work.

\section{References}

1. Sugar A, Rapuano CJ, Culbertson WW, et al. Laser in situ keratomileusis for myopia and astigmatism: safety and efficacy - a report by the American academy of ophthalmology. Ophthalmology. 2002;109(1): 175-187.

2. Varley GA, Huang D, Rapuano CJ, Schallhorn S, Wachler BSB, Sugar A. LASIK for hyperopia, hyperopic astigmatism, and mixed astigmatism - a report by the American Academy of Ophthalmology. Ophthalmology. 2004;111(8):1604-1617.

3. Stonecipher K, Ignacio TS, Stonecipher M. Advances in refractive surgery: microkeratome and femtosecond laser flap creation in relation to safety, efficacy, predictability, and biomechanical stability. Curr Opin Ophthalmol. 2006;17(4):368-372.

4. Pietilä J. Flap Creation in Laser-Assisted in Situ Keratomileusis: From Microkeratome to Femtosecond Laser. Tampere: Tampere University Press; 2012.

5. Kurtz RM, Liu X, Elner VM, Squier JA, Du D, Mourou GA. Photodisruption in the human cornea as a function of laser pulse width. J Refract Surg. 1997;13(7):653-658.

6. Sugar A. Ultrafast (femtosecond) laser refractive surgery. Curr Opin Ophthalmol. 2002;13(4):246-249.

7. Lubatschowski H. Overview of commercially available femtosecond lasers in refractive surgery. J Refract Surg. 2008;24(1):S102-S107.

8. Farjo AA, Sugar A, Schallhorn SC, et al. Femtosecond lasers for LASIK flap creation: a report by the American Academy of Ophthalmology. Ophthalmology. 2013;120(3):e5-e20.

9. Slade SG. The use of the femtosecond laser in the customization of corneal flaps in laser in situ keratomileusis. Curr Opin Ophthalmol. 2007;18(4):314-317.

10. Zhang ZH, Jin HY, Suo Y, et al. Femtosecond laser versus mechanical microkeratome laser in situ keratomileusis for myopia: metaanalysis of randomized controlled trials. J Cataract Refract Surg. 2011; 37(12):2151-2159

11. Chen S, Feng Y, Stojanovic A, Jankov MR, Wang Q. IntraLase femtosecond laser vs mechanical microkeratomes in LASIK for myopia: a systematic review and meta-analysis. J Refract Surg. 2012;28(1):15-24.

12. Jadad AR, Moore RA, Carroll D, et al. Assessing the quality of reports of randomized clinical trials: is blinding necessary? Control Clin Trials. 1996;17(1):1-12.

13. Slade SG, Durrie DS, Binder PS. A prospective, contralateral eye study comparing thin-flap LASIK (sub-Bowman keratomileusis) with photorefractive keratectomy. Ophthalmology. 2009;116(6):1075-1082.

14. Prakash G, Agarwal A, Yadav A, et al. A prospective randomized comparison of four femtosecond LASIK flap thicknesses. $J$ Refract Surg. 2010;26(6):392-402. 
15. Hatch BB, Moshirfar M, Ollerton AJ, Sikder S, Mifflin MD. A prospective, contralateral comparison of photorefractive keratectomy (PRK) versus thin-flap LASIK: assessment of visual function. Clin Ophthalmol. 2011;5:451-457.

16. Prakash G, Agarwal A, Kumar DA, et al. Femtosecond sub-bowman keratomileusis: a prospective, long-term, intereye comparison of safety

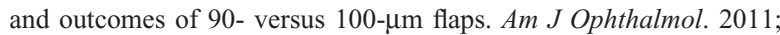
154(4):582-590.

17. He L, Liu A, Manche EE. Wavefront-guided versus wavefrontoptimized laser in situ keratomileusis for patients with myopia: a prospective Randomized Contralateral Eye Study. Am J Ophthalmol. 2014;157(6):1170-1178.

18. Ang M, Mehta JS, Rosman M, et al. Visual outcomes comparison of 2 femtosecond laser platforms for laser in situ keratomileusis. J Cataract Refract Surg. 2013;39(11):1647-1652.

19. Yu CQ, Manche EE. Comparison of 2 femtosecond lasers for flap creation in myopic laser in situ keratomileusis: one-year results. J Cataract Refract Surg. 2015;41(4):740-748.

20. Tran DB, Sarayba MA, Bor Z, et al. Randomized prospective clinical study comparing induced aberrations with IntraLase and Hansatome flap creation in fellow eyes: potential impact on wavefront-guided laser in situ keratomileusis. J Cataract Refract Surg. 2005;31(1):97-105.

21. Montes-Mico R, Rodriguez-Galietero A, Alio JL. Femtosecond laser versus mechanical keratome LASIK for myopia. Ophthalmology. 2007;114(1):62-68.

22. Tanzer DJ, Brunstetter T, Zeber R, et al. Laser in situ keratomileusis in United States Naval aviators. J Cataract Refract Surg. 2013;39(7): 1047-1058.

23. Sales CS, Manche EE. One-year outcomes from a prospective, randomized, eye-to-eye comparison of wavefront-guided and wavefrontoptimized LASIK in myopes. Ophthalmology. 2013;120(12): 2396-2402.

24. Rosman M, Hall RC, Chan C, et al. Comparison of efficacy and safety of laser in situ keratomileusis using 2 femtosecond laser platforms in contralateral eyes. J Cataract Refract Surg. 2013;39(7): 1066-1073.

25. Yu CQ, Manche EE. Comparison of 2 wavefront-guided excimer lasers for myopic laser in situ keratomileusis: one-year results. J Cataract Refract Surg. 2014;40(3):412-422.

26. Vryghem JC, Devogelaere T, Stodulka P. Efficacy, safety, and flap dimensions of a new femtosecond laser for laser in situ keratomileusis. $J$ Cataract Refract Surg. 2010;36(3):442-448.

27. Arbelaez MC, Vidal C, Arba-Mosquera S. Excimer laser correction of moderate to high astigmatism with a non-wavefront-guided aberration-free ablation profile: six-month results. J Cataract Refract Surg. 2009;35(10):1789-1798.

28. Lim DH, Keum JE, Ju WK, Lee JH, Chung TY, Chung ES. Prospective contralateral eye study to compare 80- and 120-mum flap LASIK using the VisuMax femtosecond laser. J Refract Surg. 2013; 29(7):462-468.

29. Kymionis GD, Kontadakis GA, Grentzelos MA, et al. Thin-flap laser in situ keratomileusis with femtosecond-laser technology. J Cataract Refract Surg. 2013;39(9):1366-1371.

30. Cummings AB, Cummings BK, Kelly GE. Predictability of corneal flap thickness in laser in situ keratomileusis using a $200 \mathrm{kHz}$ femtosecond laser. J Cataract Refract Surg. 2013;39(3):378-385.

31. Alio JL, Pinero DP. Very high-frequency digital ultrasound measurement of the LASIK flap thickness profile using the IntraLase femtosecond laser and M2 and Carriazo-Pendular microkeratomes. J Refract Surg. 2008;24(1):12-23.

32. Durrie DS, Stahl J. Randomized comparison of custom laser in situ keratomileusis with the Alcon Custom Cornea and the Bausch \& Lomb Zyoptix systems: one-month results. J Refract Surg. 2004;20(5): S614-S618.

33. Javaloy J, Vidal MT, Abdelrahman AM, Artola A, Alio JL. Confocal microscopy comparison of intralase femtosecond laser and Moria M2 microkeratome in LASIK. J Refract Surg. 2007;23(2):178-187.
34. Chan A, Ou J, Manche EE. Comparison of the femtosecond laser and mechanical keratome for laser in situ keratomileusis. Arch Ophthalmol. 2008;126(11):1484-1490.

35. Munoz G, Albarran-Diego C, Ferrer-Blasco T, Garcia-Lazaro S, CervinoExposito A. Long-term comparison of corneal aberration changes after laser in situ keratomileusis: mechanical microkeratome versus femtosecond laser flap creation. J Cataract Refract Surg. 2010;36(11): 1934-1944.

36. Stonecipher KG, Kezirian GM. Wavefront-optimized versus wavefrontguided LASIK for myopic astigmatism with the ALLEGRETTO WAVE: three-month results of a prospective FDA trial. J Refract Surg. 2008;24(4):S424-S430.

37. Pfaeffl WA, Kunze M, Zenk U, Pfaeffl MB, Schuster T, Lohmann C. Predictive factors of femtosecond laser flap thickness measured by online optical coherence pachymetry subtraction in sub-Bowman keratomileusis. J Cataract Refract Surg. 2008;34(11):1872-1880.

38. Rosa AM, Neto MJ, Quadrado MJ, et al. Femtosecond laser versus mechanical microkeratomes for flap creation in laser in situ keratomileusis and effect of postoperative measurement interval on estimated femtosecond flap thickness. J Cataract Refract Surg. 2009; 35(5):833-838.

39. Zhai CB, Tian L, Zhou YH, Zhang QW, Zhang J. Comparison of the flaps made by femtosecond laser and automated keratomes for sub-bowman keratomileusis. Chin Med J (Engl). 2013;126(13):2440-2444.

40. Ahn H, Kim JK, Kim CK, et al. Comparison of laser in situ keratomileusis flaps created by 3 femtosecond lasers and a microkeratome. J Cataract Refract Surg. 2011;37(2):349-357.

41. Patel SV, Maguire LJ, McLaren JW, Hodge DO, Bourne WM. Femtosecond laser versus mechanical microkeratome for LASIK: a randomized controlled study. Ophthalmology. 2007;114(8):1482-1490.

42. Zhou Y, Zhang J, Tian L, Zhai C. Comparison of the Ziemer FEMTO LDV femtosecond laser and Moria M2 mechanical microkeratome. J Refract Surg. 2012;28(3):189-194.

43. Holzer MP, Rabsilber TM, Auffarth GU. Femtosecond laser-assisted corneal flap cuts: morphology, accuracy, and histopathology. Invest Ophthalmol Vis Sci. 2006;47(7):2828-2831.

44. Krueger RR, Dupps WJ Jr. Biomechanical effects of femtosecond and microkeratome-based flap creation: prospective contralateral examination of two patients. J Refract Surg. 2007;23(8):800-807.

45. von Jagow JB, Kohnen T. Corneal architecture of femtosecond laser and microkeratome flaps imaged by anterior segment optical coherence tomography. J Cataract Refract Surg. 2009;35(1):35-41.

46. Vaddavalli PK, Yoo SH. Femtosecond laser in-situ keratomileusis flap configurations. Curr Opin Ophthalmol. 2011;22(4):245-250.

47. Srivannaboon S, Sunlakaviset P, Kosrirukvongs P, et al. Refractive outcomes of femtosecond LASIK for myopic correction at Siriraj Hospital, Thailand. J Med Assoc Thai. 2012;95(suppl 4):S18-S23.

48. Kezirian GM, Stonecipher KG. Comparison of the IntraLase femtosecond laser and mechanical keratomes for laser in situ keratomileusis. J Cataract Refract Surg. 2004;30(4):804-811.

49. Binder PS. Flap dimensions created with the IntraLase FS laser. J Cataract Refract Surg. 2004;30(1):26-32.

50. Durrie DS, Kezirian GM. Femtosecond laser versus mechanical keratome flaps in wavefront-guided laser in situ keratomileusis: prospective contralateral eye study. J Cataract Refract Surg. 2005;31(1):120-126.

51. Lifshitz T, Levy J, Klemperer I, Levinger S. Anterior chamber gas bubbles after corneal flap creation with a femtosecond laser. J Cataract Refract Surg. 2005;31(11):2227-2229.

52. Srinivasan S, Rootman DS. Anterior chamber gas bubble formation during femtosecond laser flap creation for LASIK. J Refract Surg. 2007;23(8):828-830.

53. Srinivasan S, Herzig S. Sub-epithelial gas breakthrough during femtosecond laser flap creation for LASIK. Br J Ophthalmol. 2007; 91(10):1373.

54. Kaiserman I, Maresky HS, Bahar I, Rootman DS. Incidence, possible risk factors, and potential effects of an opaque bubble layer created by a femtosecond laser. J Cataract Refract Surg. 2008;34(3):417-423. 
55. Kanellopoulos AJ, Asimellis G. Digital analysis of flap parameter accuracy and objective assessment of opaque bubble layer in femtosecond laser-assisted LASIK: a novel technique. Clin Ophthalmol. 2013; 7:343-351.

56. Stonecipher KG, Dishler JG, Ignacio TS, Binder PS. Transient light sensitivity after femtosecond laser flap creation: clinical findings and management. J Cataract Refract Surg. 2006;32(1):91-94.

57. Munoz G, Albarran-Diego C, Sakla HF, Javaloy J, Alio JL. Transient light-sensitivity syndrome after laser in situ keratomileusis with the femtosecond laser incidence and prevention. J Cataract Refract Surg. 2006;32(12):2075-2079.
58. Krueger RR, Thornton IL, Xu M, Bor Z, van den Berg TJ. Rainbow glare as an optical side effect of IntraLASIK. Ophthalmology. 2008;115(7): 1187-1195.

59. Bamba S, Rocha KM, Ramos-Esteban JC, Krueger RR. Incidence of rainbow glare after laser in situ keratomileusis flap creation with a $60 \mathrm{kHz}$ femtosecond laser. J Cataract Refract Surg. 2009;35(6):1082-1086.

60. Gatinel D, Saad A, Guilbert E, Rouger H. Unilateral rainbow glare after uncomplicated femto-LASIK using the FS-200 femtosecond laser. J Refract Surg. 2013;29(7):498-501.
Clinical Ophthalmology

\section{Publish your work in this journal}

Clinical Ophthalmology is an international, peer-reviewed journal covering all subspecialties within ophthalmology. Key topics include: Optometry; Visual science; Pharmacology and drug therapy in eye diseases; Basic Sciences; Primary and Secondary eye care; Patient Safety and Quality of Care Improvements. This journal is indexed on

\section{Dovepress}

PubMed Central and CAS, and is the official journal of The Society of Clinical Ophthalmology (SCO). The manuscript management system is completely online and includes a very quick and fair peer-review system, which is all easy to use. Visit http://www.dovepress.com/ testimonials.php to read real quotes from published authors. 